\title{
Proliferating Trichilemmal Tumor: A Case on the Nose of a 70-Year-Old Man
}

\author{
Marcius A. Peryassu ${ }^{a} \quad$ Bernardo C. Peryassu ${ }^{a} \quad$ Raphael C. Peryassu ${ }^{a}$ \\ Juan Piñeiro-Maceira ${ }^{b} \quad$ Marcia Ramos-e-Silva ${ }^{c}$ \\ ${ }^{a}$ Private Practice, ${ }^{b}$ Sector of Pathology, and ${ }^{c}$ Sector of Dermatology and Post-Graduation \\ Course, University Hospital and School of Medicine, Federal University of Rio de Janeiro, \\ Rio de Janeiro, Brazil
}

\section{Key Words}

Cyst $\cdot$ Neoplasia $\cdot$ Trichilemmal tumor $\cdot$ Proliferating trichilemmal tumor

\begin{abstract}
The authors report a case of proliferating trichilemmal tumor on the tip of the nose of a man. This tumor is usually seen in women and on the scalp, and it shows trichilemmal keratinization on histopathology.

(c) 2013 S. Karger AG, Basel
\end{abstract}

\section{Introduction}

In 1966, Jones described a special type of cyst, which he called proliferating trichilemmal tumor. The tumor's major histopathological feature was the presence of trichilemmal keratinization, i.e., the sudden change from nucleated epithelial cells to anucleated cells in the absence of a granular layer [1]. Since this first description, many other names have been assigned to this disease: subepidermal acanthoma, invasive hair matrix tumor, invasive pilomatrixoma, trichochlamydocarcinoma, hydatidiform keratinous cyst, giant hair matrix tumor, trichochlamydoacanthoma, and pillar cyst [2].

Proliferating trichilemmal tumor appears mainly in women over the age of 60 years and is in general a solitary lesion on the scalp [3]. It rarely occurs in other regions, and there are only few reports on young patients [3]. 
Peryassu et al.: Proliferating Trichilemmal Tumor: A Case on the Nose of a 70-Year-Old Man

\section{Case Report}

A 70-year-old white man, born in Buenos Aires, Argentina, visited for a consultation about a localized swelling on the tip of his nose and an external orifice with serosanguineous discharge (fig. 1, fig. 2). Our initial hypothesis was a furuncular myiasis, since the patient had been to a rural area and had lived in a heavily wooded area with a plantation. The patient was treated with a single dose of $18 \mathrm{mg}$ ivermectin, which was repeated 1 week later.

When he returned 2 months later, his clinical status was unchanged. Although it did not look like a sebaceous cyst, the orifice produced a sebaceous secretion. At this point, an excisional biopsy was performed, removing a large part of the lesion followed by curettage. Histopathology showed follicular hyperkeratosis and, in the dermis, prominent sebaceous glands, telangiectasic capillaries, and a diffuse mononuclear inflammatory reaction. Also, a 'cystically' dilated infundibular structure was observed, whose wall showed squamous cell proliferation with wide eosinophilic cytoplasm, pleomorphic nuclei, and prominent nucleoli as well as extensive dyskeratosis-forming masses of cells with areas of necrosis. This histopathological picture was interpreted as suggestive of adnexal neoplasia with pilar differentiation and a possible proliferating epidermoid cyst (fig. 3, fig. 4, fig. 5).

The lesion had already relapsed 45 days later, and another surgery was performed (fig. 6). This time, part of the alar cartilage was removed and the reconstruction was done with a dorsal nasal flap. Histopathology showed a complete excision of the lesion. The patient has been monitored since then without a recurrence of the lesion (fig. 7).

After the last surgery, prostate cancer was diagnosed, and the patient was submitted to radical prostatectomy and radiotherapy. After this surgery, he suffered from deep vein thrombosis and needed to take anticoagulants. He also had intestinal cancer, making the removal of $25 \mathrm{~cm}$ of the large bowel necessary. One year before the appearance of these 2 malignant tumors, the patient had developed a severe mental depression due to his mother's ill health and eventual death.

\section{Discussion}

Trichilemmal cysts originate from the external hair sheath and may lead to so-called proliferative cysts [4], initially called proliferating epidermoid cysts [1]. They are characterized by trichilemmal keratinization, i.e., the sudden change from nucleated epithelial cells to anucleated cells in the absence of a granular layer [1-3]. Proliferating trichilemmal tumors generally have a benign clinical course, and a histological differentiation from squamous cell carcinoma is often difficult. Moreover, these tumors can sometimes be aggressive with a high mortality rate $[5,6]$. They are more common in women over the age of 60 years, and in $90 \%$ of the cases they occur as a solitary lesion on the scalp [2,3].

These tumors may also affect the neck, trunk, groin, pubis, vulva, upper and lower extremities, shoulder, back of the hand, index finger, face, forehead, nose, eyelids, lips, oral cavity, jaw skull base, and gluteal region [2, 3]. In 2012, there was a case report from Portugal on a lesion on the nose of a woman [7]. The clinical differential diagnosis should include epidermoid cyst, keratoacanthoma, squamous cell carcinoma, pilomatrixoma, sweat gland tumor, cylindroma, basal cell carcinoma, and angiosarcoma [2]. Trichilemmal cysts comprise about $20 \%$ of all cysts, the remaining are epidermoid cysts. The origin of the tumor is probably the isthmus of a hair follicle, and benign and malignant areas can be seen in 1 tumor. Trauma or infection is believed to stimulate a malignant transformation. It is also 
Peryassu et al.: Proliferating Trichilemmal Tumor: A Case on the Nose of a 70-Year-Old Man

important to mention that our patient is a man with a lesion on the nose, and the great majority of reported cases are on women and on the scalp.

Our patient's multiple organ cancer may be due to an imbalance in his immune system after an episode of severe depression. Further studies should be carried out to find molecular evidence of this carcinogenesis. The patient is still being monitored, and so far there has been no sign of relapse. The therapy of choice for this tumor is surgery, and we believe that a wide margin of safety should be used, since relapses are common as in our patient.

\section{References}

1 Jones EW: Proliferating epidermoid cysts. Arch Dermatol 1966;94:11-19.

-2 Satyaprakash AK, Sheehan DJ, Sangüeza OP: Proliferating trichilemmal tumors: a review of the literature. Dermatol Surg 2007;33:1102-1108.

3 Cavaleiro LH, Viana Fde O, Carneiro CM, Miranda MF: Proliferating trichilemmal tumor - case report. An Bras Dermatol 2011;86:S190-S192.

4 Pinkus H: 'Sebaceous cysts' are trichilemmal cysts. Arch Dermatol 1969;99:544-555.

-5 Tierney E, Ochoa MT, Rudkin G, Soriano TT: Mohs' micrographic surgery of a proliferating trichilemmal tumor in a young black man. Dermatol Surg 2005;31:359-363.

-6 Goyal S, Jain BB, Jana S, Bhattacharya SK: Malignant proliferating trichilemmal tumor. Indian J Dermatol 2012;57:50-52.

-7 Rosmaninho A, Caetano M, Oliveira A, Pinto de Almeida T, Selores M, Alves R: Tumor triquilemal proliferante do nariz. An Bras Dermatol 2012;87:914-916.

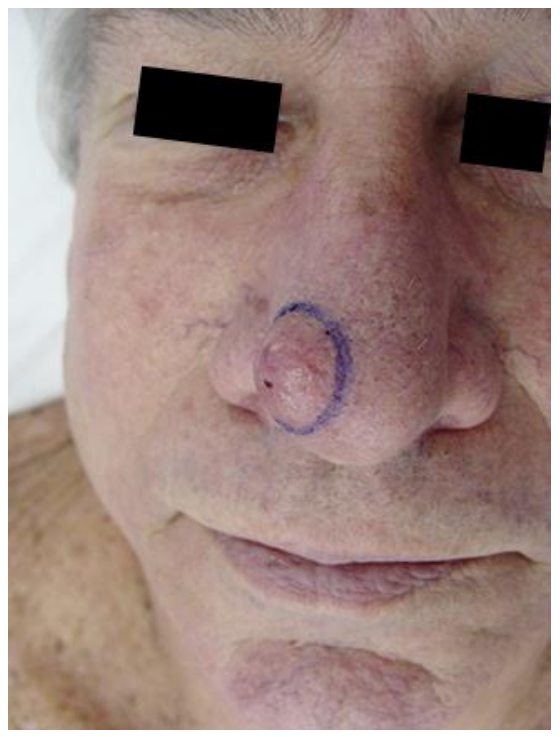

Fig. 1. Proliferating trichilemmal tumor on the nose of a man. 
Case Reports in
Dermatology

Case Rep Dermatol 2013;5:248-253

DOI: 10.1159/000355201

(C) 2013 S. Karger AG, Basel

Peryassu et al.: Proliferating Trichilemmal Tumor: A Case on the Nose of a 70-Year-Old Man

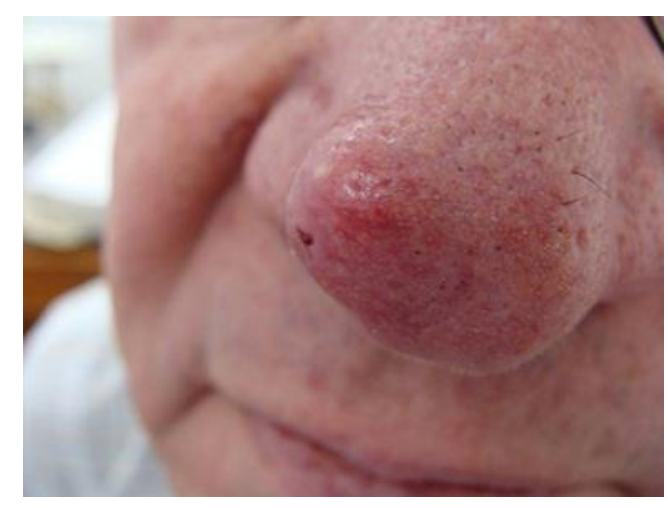

Fig. 2. Close-up of the lesion.

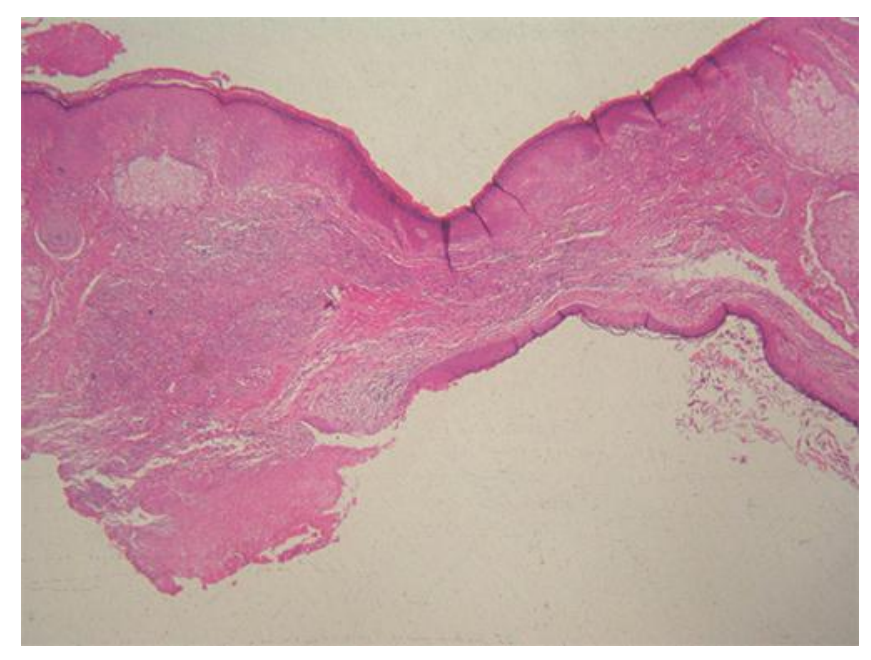

Fig. 3. Wall of the intradermal cystic structure, covered by stratified pavimentary epithelium, partly with and partly without the formation of a granular layer, and with larger cells (HE, ×40). 
Peryassu et al.: Proliferating Trichilemmal Tumor: A Case on the Nose of a 70-Year-Old Man

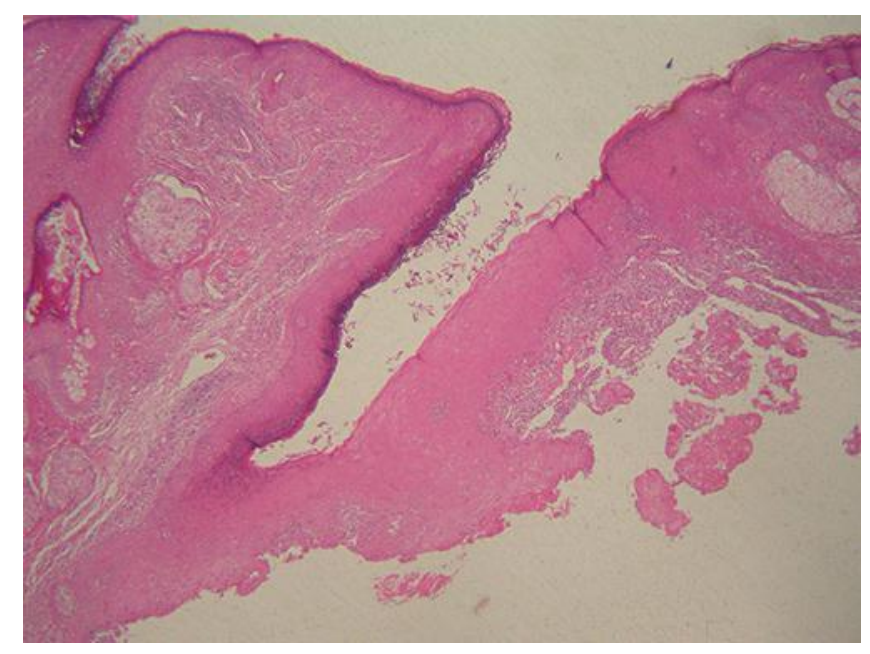

Fig. 4. Detail of the cystic wall in relation to the infundibular structure $(\mathrm{HE}, \times 100)$.

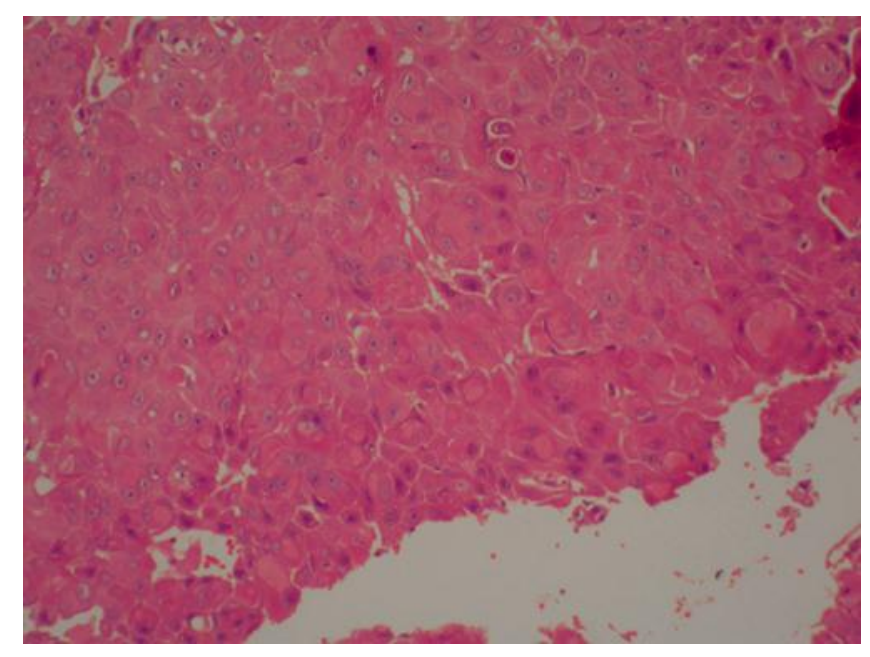

Fig. 5. Detail of the solid portion of the neoplasia, composed of large cells with eosinophilic cytoplasma, prominent nucleoli, and atypical cells to a moderate degree $(\mathrm{HE}, \times 400)$. 
Case Reports in
Dermatology

Case Rep Dermatol 2013;5:248-253

DOI: 10.1159/000355201

(C) 2013 S. Karger AG, Basel

www.karger.com/cde

Peryassu et al.: Proliferating Trichilemmal Tumor: A Case on the Nose of a 70-Year-Old Man

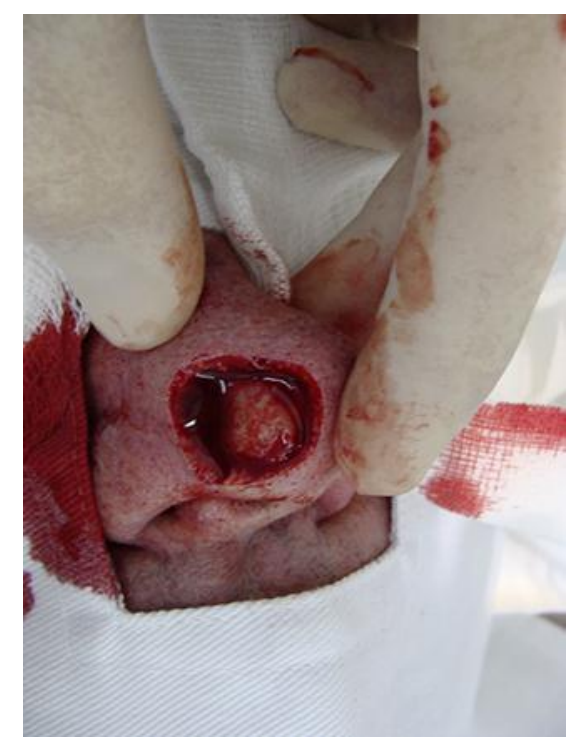

Fig. 6. Aspect immediately after total surgical removal.

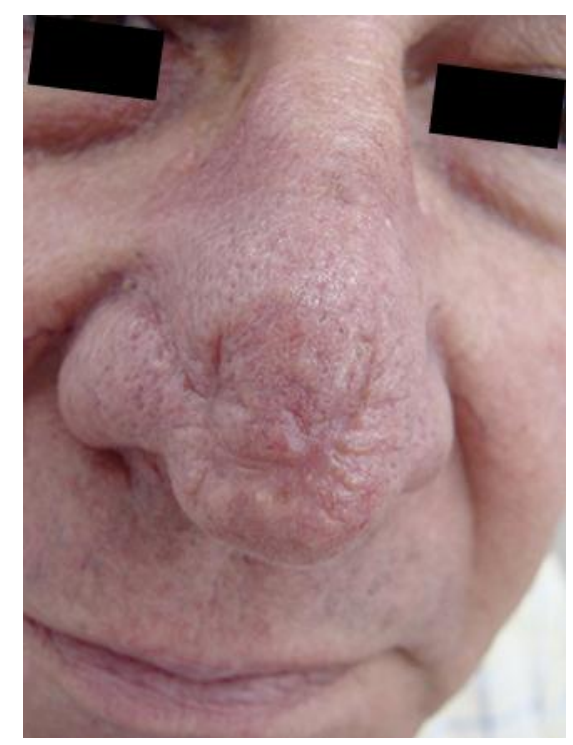

Fig. 7. Four months after the removal of the tumor. 